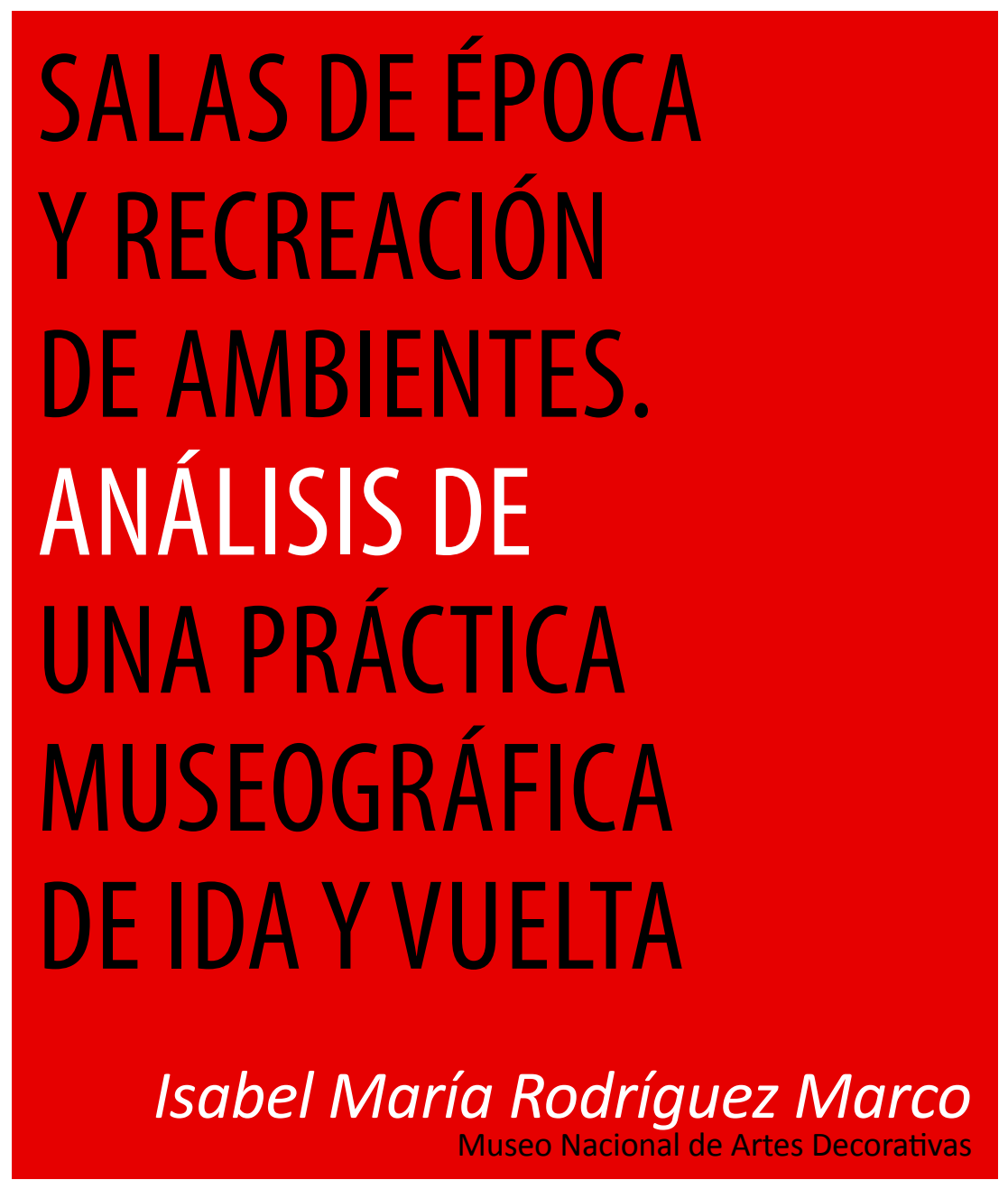

\title{
A MODO DE INTRODUCCIÓN
}

La museología posmoderna ha subrayado la necesidad de deconstruir el museo, su lenguaje, sus interpretaciones de las colecciones y abordar de manera crítica la actuación de la institución a lo largo de su historia y en el presente. Para establecer una comunicación real con el visitante y trabajar con transparencia y honestidad intelectual, se hace preciso hacer explícito el discurso del museo ${ }^{1}$.

El museo es una institución contradictoria; alberga objetos desgajados de su contexto original -un contexto que, por otra parte, ha podido sufrir varias transformaciones a lo largo del tiempo- y se esfuerza en aportar al visitante toda la información y los recursos que le permitan reconstruirlo. Por otra parte, al ingresar en el museo, las piezas se cargan de nuevos y múltiples significados en la interacción con el edificio, con las colecciones circundantes, con los visitantes, mediante el uso que se les da y según el planteamiento museográfico con el que se trabaje. 
El Museo Nacional de Artes Decorativas está en pleno proceso de remodelación y redefinición, lo que nos ha impulsado a reflexionar sobre la evolución de la exposición permanente del museo a lo largo de su historia y sus posibles fuentes; con el deseo de llegar a comprender su intencionalidad hemos abordado este trabajo.

Por otra parte, venimos observando un creciente interés por el análisis de la museografía de recreación de ambientes y salas de época, materializándose en la celebración de varios congresos internacionales: en el Bowes Museum (Barnard Castle, Reino Unido) en 2014, en el Museo Cerralbo y en la Academia de Ciencias de Bolonia en 2016 por citar los más recientes.

\section{SALAS DE ÉPOCA: ORIGEN Y DESARROLLO}

El término period room -que hemos traducido como sala de época- ha sido utilizado para designar aquellas estancias -la decoración y elementos de cierre (como panelados y techumbres de madera, ventanas y puertas)- que han sido instaladas en un museo tras ser retiradas de su ubicación original. Por extensión, también se refiere con la expresión period rooms a salas en las que se reconstruye un interior de un determinado momento histórico por medio de objetos originales que han sido agrupados de manera artificial en el museo.

Estos montajes aparecieron durante el último tercio del siglo XIX y tuvieron su máximo auge en las tres primeras décadas del siglo XX. Por su mayor implantación en los museos anglosajones se considera un aspecto diferenciador de la museografía americana e inglesa, con respecto a la europea continental².

En La Museología de Rivière, en el capítulo dedicado a analizar la situación de los museos en Europa y América del Norte a finales del siglo XIX, se incluye un texto de G. Bazin sobre las period rooms ${ }^{3}$ que resume el concepto y desarrollo de ese modelo museográfico. G. Bazin ${ }^{4}$ subraya la diferencia de puntos de vista entre los profesionales americanos y europeos en relación a la importancia que se concede a la contextualización de las piezas expuestas en los museos. Bazin define con claridad las salas de época, interiores transportados desde Europa a Estados Unidos y las relaciona con los museos ambientados, en los que los objetos se exponen en salas dispuestas con un estilo de una época concreta, como fue el caso de la instalación del Museo Nacional de Zúrich de finales del siglo XIX ${ }^{5}$.

Bazin considera que, a diferencia de los europeos, los visitantes americanos necesitan reconstrucciones que evoquen tiempos pasados, para poder entender los objetos. Esta tendencia museográfica se inicia en la exposición que llevó a cabo en 1924 el Metropolitan Museum de Nueva York sobre los estilos coloniales americanos y que luego fue convertida en la American Wing del museo 6 .

Por otra parte, Bazin señala que en el Museo de Bellas Artes de la Ciudad de París (Petit Palais) también existe un conjunto de period rooms, las salas del siglo XVIII legadas por Edward Tuck7. Actualmente no se presentan como period rooms, pues las piezas tienen procedencias diversas. Las colecciones (pintura, porcelana, mobiliario, tapices y otros objetos del siglo XVIII) se exponen de manera que las piezas destacan por su propia especificidad, aunque el panelado refuerza la visión armónica de conjunto.

Curiosamente, Bazin no señaló el conjunto de interiores parisinos conservados en el Museo Carnavalet (Fig. 1), precursor de las period rooms, puesto que desde la temprana fecha de 1878, numerosos interiores fueron trasladados al museo para evitar su desaparición.

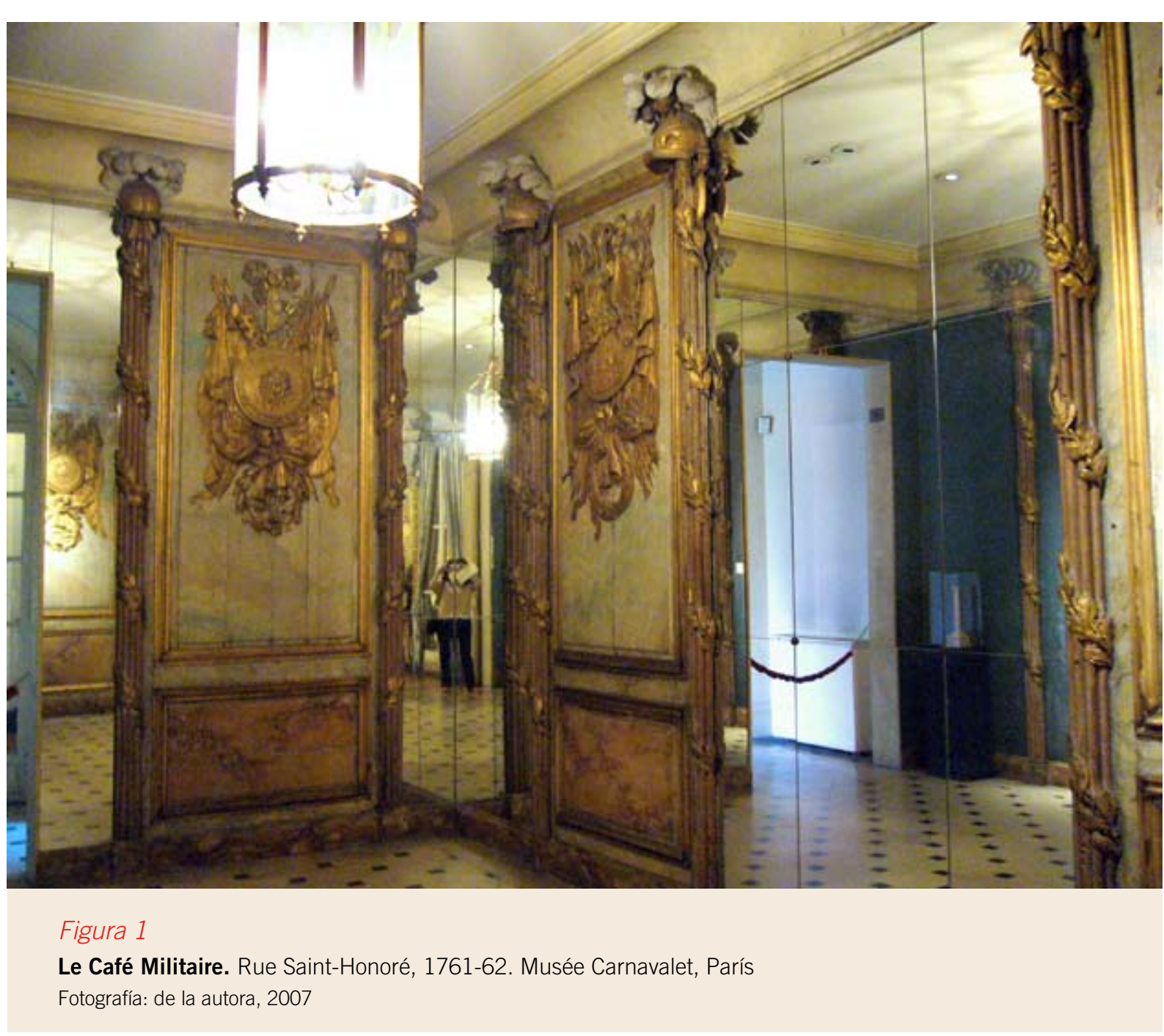

El museo Victoria \& Albert de Londres ${ }^{9}$, desde las primeras décadas de su historia y hasta principios del siglo $\mathrm{XX}$, adquirió panelados y trabajos de arquitectura en madera, unas veces como habitaciones completas, otras como pedazos resultantes de la división de aquéllas. En una gran proporción provenían de Francia, considerada la nación con mejores producciones artísticas, y eran utilizadas como ejemplo para los artesanos ingleses.

Hacia 1890 en la política de adquisiciones del museo se advierte una corriente nacionalista, centrándose en las producciones inglesas de los siglos XVII y XVIII. Además, existía una voluntad de preservación de interiores que corrían el riesgo de ser destruidos. El museo compró alguna de estas habitaciones en el mercado del arte, pero otras fueron trasladadas al museo directamente desde casas históricas de Londres antes de 
que fueran demolidas. Entre 1890 y 1920 esta preocupación por el patrimonio arquitectónico inglés fue tan importante que se puso en marcha un proyecto de creación de una serie enciclopédica de habitaciones inglesas. En las English Primary Galleries se instalaron ocho period rooms. El museo se había reorganizado entre Primary y Study Galleries, con diferentes presentaciones museográficas, una diferenciación que ha sobrevivido hasta hace muy poco tiempo ${ }^{10}$.

En los Estados Unidos de América son numerosísimos los museos que cuentan con salas de época desde la década de 1920. En el Museo de Philadelphia, considerado en la época como un modelo para el resto de museos americanos, se diferenciaba entre salas de estudio, enfocadas a la visita de especialistas y salas de época, destinadas al público general:

"Le principal étage du musée est celui que le public est invité à visiter; il comporte des salles où les objets sont répartis dans l'ordre chronologique pour que les visiteurs trouvent successivement des ensembles leur faisant comprendre l'histoire et l'évolution des beaux-arts et des arts décoratifs du monde entier. Chacun des divers ensembles réunit toutes les expressions artistiques d'une période déterminée. Peintures, gravures, boiseries, meubles, tapis, tissus, céramiques sont harmonieusement disposés pour faire appel à l'imagination. Ces galeries sont bordées par des salles où ont été reconstitués des intérieurs anciens de diverses époques, au moyen d'éléments authentiques: panneaux, peintures, tentures." 11

Este fragmento describe perfectamente cuál era el criterio de estas ambientaciones: crear conjuntos que funcionaran como un desencadenante en el visitante de su imaginación. No había una excesiva preocupación porque las piezas expuestas concordasen entre sí y correspondieran a un interior real. En cambio, sí que se expresa una intención didáctica sobre la evolución de las artes que pretendían lograr a base de esta museografía ambiental. Sí que parece que aprecien la autenticidad de lo expuesto de un modo mucho más enfático en las salas periféricas. En las salas de estudio, las piezas están clasificadas por materias y su localización, cercana a las áreas de trabajo de documentación, biblioteca y fotografía, facilitaba su uso por parte de estudiantes e investigadores.

M. Richard F. Bach -comisario de las exposiciones sobre diseño americano del Metropolitan Museum de Nueva York entre los años 1917 y $1940^{12}$ - en su crónica sobre el Institute of Arts de Detroit ponía de relieve que este modo de exposición deleita al visitante:

"La nouvelle manière de présenter les collections consiste, en effet, à choisir des spécimens appartenant à une période donnée; ceux-ci sont ensuite placés, soit dans un cadre approprié et authentique comme, par exemple, une chambre faisant partie d'une maison du XVIIe siècle, soit dans un milieu qui reproduise exactement un modèle existant (...)". "Les galeries du premier étage, qui est de beaucoup le plus important, présentent une variété d'aspects qui enchante le visiteur"15.

El Metropolitan Museum de Nueva York, antes de que se creara la American Wing, ya en 1903 adquirió un dormitorio romano antiguo procedente de una villa cercana a
Pompeya (Boscoreale room); en 1906, una habitación panelada en madera del siglo XVII originaria de Flims (Suiza) y un dormitorio del siglo XVIII del palacio Sagredo de Venecia. Además, podemos citar las salas Wrightsman (conjunto de interiores franceses), las English rooms, el Studiolo de Gubbio, una sala de recepción procedente de una casa de Damasco de 1707, un salón completamente amueblado de Frank Lloyd Wright (1912-1915) y los claustros medievales de The Cloisters ${ }^{16}$. En algunas de las salas todo lo expuesto es auténtico y en otras se hace una interpretación de lo que en otro tiempo pudo haber sido un interior real. Los conservadores que trabajaron en las period rooms del MET estuvieron influidos por las corrientes decorativas de su tiempo, como sucede en la Powel Room, que responde al auge del revival colonial de la década de $1920^{17}$.

Quisiéramos mencionar aquí un ejemplo curioso de period rooms que ilustra el gusto que imperaba en los Estados Unidos durante el primer tercio del siglo XX. Se trata de las salas en miniatura de la coleccionista Thorne, conservadas en el Art Institute de Chicago. Fueron realizadas en 1932 y 1940 y recrean interiores americanos, europeos (ingleses y franceses) y orientales ${ }^{18}$. El museo ha sabido aprovechar este conjunto como sala didáctica, disponiendo un peldaño en el perímetro que ayuda a los niños a asomarse a estas ventanitas sorprendentes (Figs. 2).

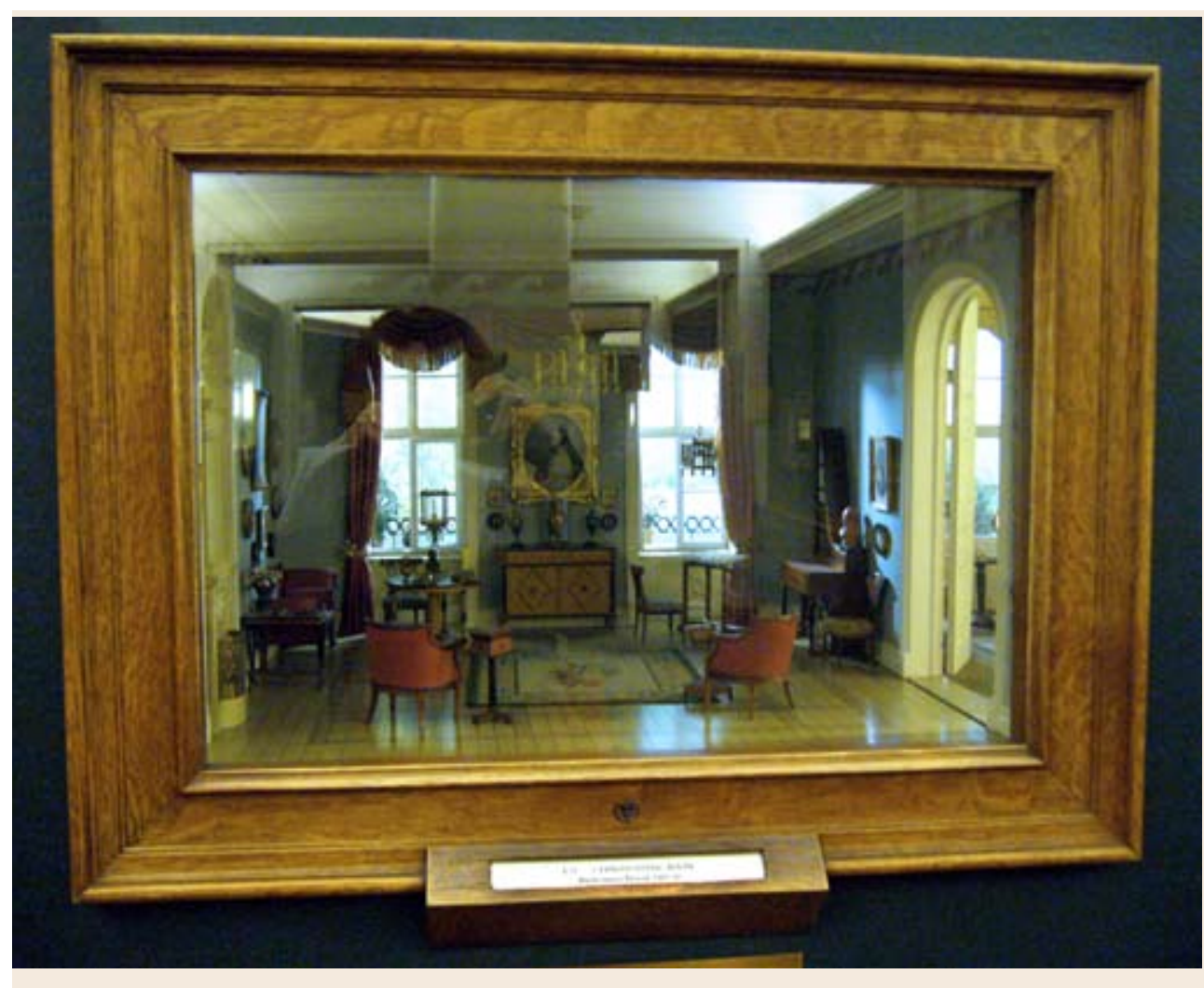
Figuras 2 Thorne Rooms. Art Institute, Chicago Fotografías: de la autora, 2007
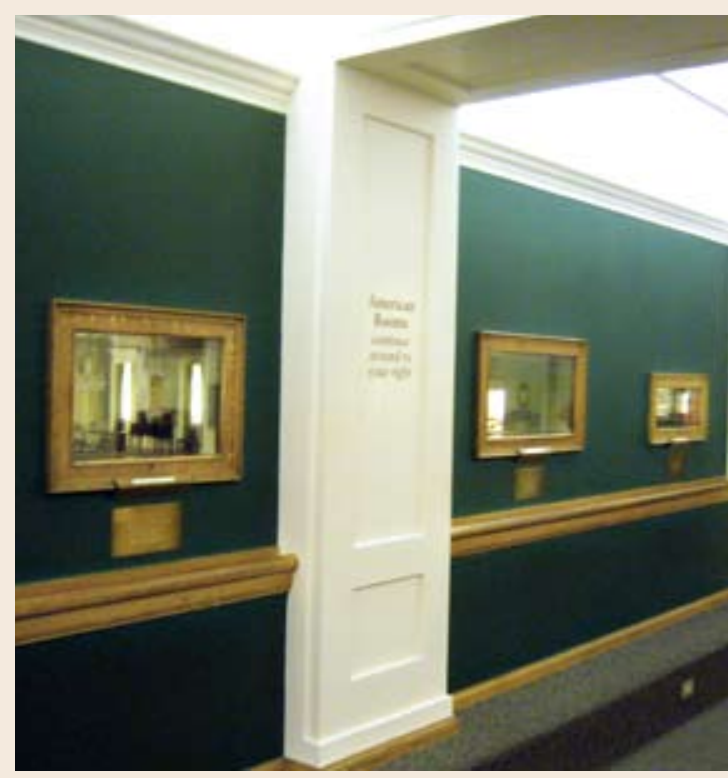
Hans Haug, conservador de museos de Estrasburgo ${ }^{19}$, era partidario de exponer los objetos en ambientes, oponiéndose claramente a la posición dominante en la década de 1930, en la que la museografía moderna abogaba por el aislamiento de las obras de arte en las salas, con el fin de asegurar la neutralidad del medio en el que el espectador contempla las obras.

Léo van Puyvelde, conservador de los Museos Reales de Bellas Artes de Bruselas, por el contrario, desaconseja el museo sintético a la manera norteamericana; considera que, sobre todo en relación con los museos de arte, basta con evocar el ambiente introduciendo algún objeto en armonía con las obras, con el fin de no alterar su integridad estética ${ }^{20}$. Esta posición, tal y como señala Javier Gómez Martínez supone una posición intermedia entre la escenificación a la americana y la neutralidad moderna ${ }^{21}$. Manuel Escrivá de Romaní, asistente a la Conferencia de Madrid organizada por la Oficina Internacional de Museos en 1934, se expresaba en esa misma dirección ${ }^{22}$

Georges Henri Rivière realizó un informe para el Consejo Internacional de Museos en 1949 sobre el Victoria \& Albert, que había sido remodelado tras la Segunda Guerra Mundial23. Las colecciones del museo se exponían siguiendo tres modelos museográficos: tecnológico (materias y técnicas), cronológico y realista. Éste último interesó especialmente a Rivière. Este tipo de presentación agrupaba objetos que formaron o pudieron formar parte de un mismo conjunto histórico. Una manera de exponer las piezas en el museo que se había explorado con especial énfasis en América, según Rivière, porque el público americano necesitaba la evocación del interior histórico.

En el Victoria \& Albert, desde entonces, una serie de factores transformaron el punto de vista de los conservadores hacia estas salas. Cada vez había más casas históricas abiertas al público y el control de las intervenciones urbanísticas favoreció una mayor protección del patrimonio, por lo que el museo ya no tenía que acudir al rescate de estos espacios históricos. Por otro lado, la extensión del museo con la adquisición de la Apsley House, Ham House y Osterley, trasladó a esas casas los esfuerzos de los técnicos del museo ${ }^{24}$. A pesar de su popularidad entre los visitantes, tan sólo dos habitaciones más se incorporaron a la colección del V\&A: una sala victoriana procedente de The Grove, adquirida en 1963, y el despacho panelado en madera diseñado por Frank Lloyd Wright para Edgar J. Kaufman. Hay que añadir a lo ya comentado, que los avances en la investigación permitieron conocer que algunas habitaciones estaban formadas por fragmentos agrupados artificialmente por los anticuarios a quienes se compró estas piezas, por lo que se abrió un debate en torno a su autenticidad.

Germain Bazin hace un resumen de los aspectos negativos que se han señalado incluso en América, allí donde las salas de época han tenido mayor predicamento:

"Esa forma de presentación ha sido muy criticada incluso en América; tiene, en efecto, múltiples inconvenientes. Anquilosa el museo, haciendo difíciles y costosas las transformaciones futuras; la iluminación, tanto natural como artificial, suele ser insuficiente, si se quiere respetar el ambiente de época, lo que perjudica mucho las pinturas allí presentadas, por otra parte casi siempre están demasiado lejos de la vista del espectador; los objetos preciosos no pueden protegerse en una vitrina, pues se perjudicaría el ambiente; la rotu- lación de las obras es poco práctica y la circulación del público incómoda debido a la estrechez de las salidas; además, la división del museo en pequeñas salas sucesivas hace más difícil la vigilancia"25.

En el Metropolitan de Nueva York, tal y como ocurrió en el caso del V\&A, entre los años 1950 y 1980 este tipo de salas dejaron de interesar a los especialistas, puesto que surgieron dudas acerca de su autenticidad y las condiciones de conservación de las obras originales. Pero a partir de los años ochenta se reevaluó su importancia26.

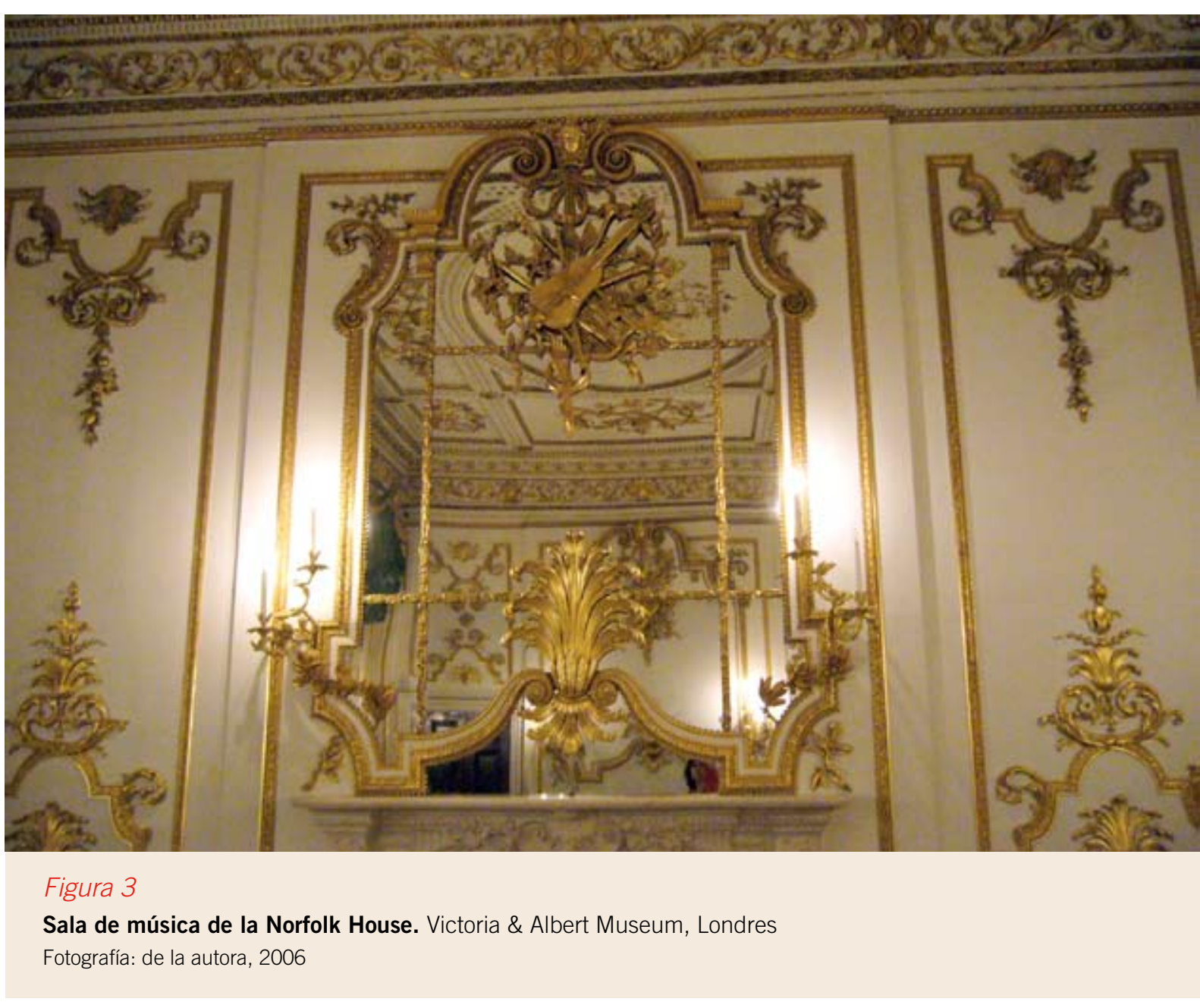

Cuando el museo Victoria \& Albert abordó la remodelación de las salas de artes decorativas británicas, cinco salas completas fueron instaladas (Fig. 3) y fragmentos de otras cinco, aunque esta vez expuestas como objetos, con el fin de aportar a los visitantes la oportunidad de experimentar en tres dimensiones algunos espacios relevantes dentro de la historia de la arquitectura. Sarah Medlam, conservadora del V\&A que ha coordinado el montaje de las period rooms, considera que para muchos visitantes que no tienen un gran conocimiento histórico y para quienes los montajes de los museos pueden ser difíciles de entender, las period rooms pueden sugerir muy bien el contexto social. Estas salas pueden evocar una atmósfera particular que sugiere modos de vida del pasado, lo que puede ayudar al visitante a conectar con sus propias experiencias. Un estudio de público realizado en las salas antiguas en 1997 subrayaba la popularidad de las period rooms y su importancia para la explicación de la evolución de los estilos domésticos; asimismo se apunta que proporcionan variedad y descanso en la visita al museo 27. 


\section{RECREACIÓN DE AMBIENTES}

La museografía de las salas de época ha influido en la instalación de muchos tipos de museos, de una u otra manera, bien para aproximarse a ese modo de exponer las piezas, como para alejarse radicalmente del mismo. Los museos de historia, de artes decorativas, las casas museo, así como la musealización de edificios históricos han bebido de la experiencia de las period rooms a la hora de interpretar los interiores. Estos diferentes tipos de museos se nutren mutuamente en todas sus funciones: investigación exposición, conservación, interpretación y difusión.

Desde hace algunos años, ha resurgido un interés hacia la reconstrucción de interiores, con el Victoria \& Albert Museum como institución de referencia, pues ha logrado un difícil equilibrio entre las necesidades de conservación, de rigor histórico y de didáctica (Fig. 4). En las salas dedicadas al Barroco en Europa, renovadas recientemente, se han incluido interiores históricos con un fin concreto, explicar la nueva noción de comodidad que aparece en el siglo XVIII28.
La necesidad de facilitar la visita a los museos de un público más amplio, así como el interés por parte de los investigadores y los profesionales de los museos de hacer a los objetos reencontrarse con su contexto de uso ha motivado que la exposición permanente de muchos museos y las exposiciones temporales estén manifestando un clarísimo acercamiento al planteamiento museográfico de la reconstrucción de ambientes. A modo de ejemplo, vamos a señalar la sala dedicada a los artistas prerrafaelistas de la Galería de Arte de Mánchester (Fig. 5), en la que se ha incluido un conjunto de objetos de artes decorativas que son piezas relevantes en sí mismas, como manifestación artística de aquel movimiento cultural, pero que también nos están permitiendo evocar en cierta manera, cómo convivían las pinturas con los objetos que coleccionaban los clientes de los artistas prerrafaelistas (además de cerámicas, muebles y otros objetos contemporáneos, cerámicas orientales).

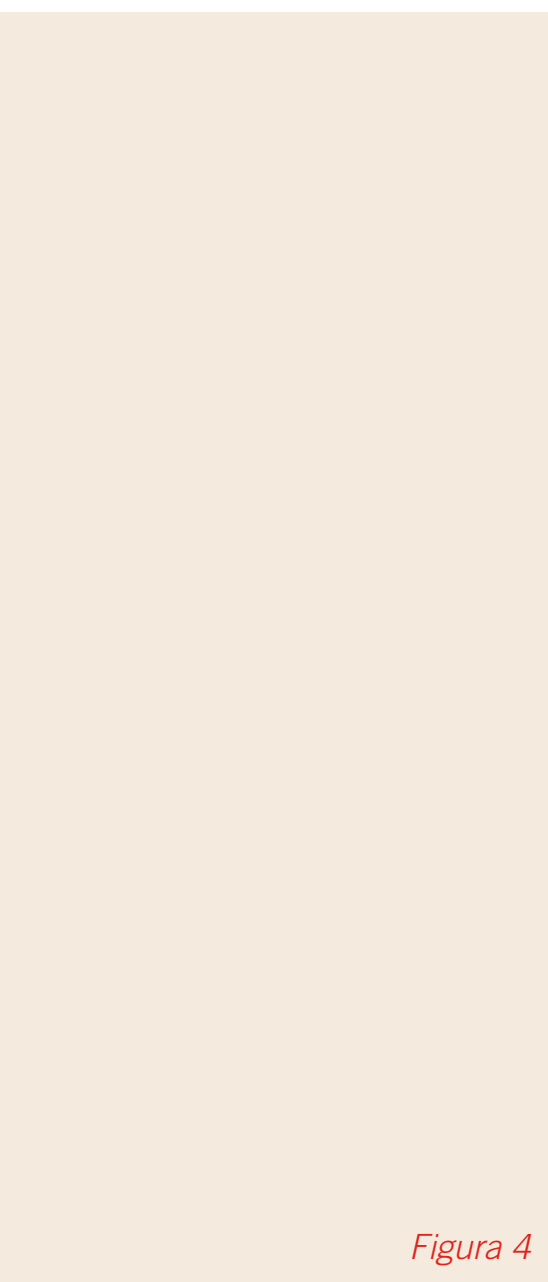

Gabinete pintado del p Antoine Megret de Sérilly. París, siglo XVIII (Europa, 1600-1815). Victoria \& Albert Museum, Londres Fotografía: Ana Cabrera, 2016

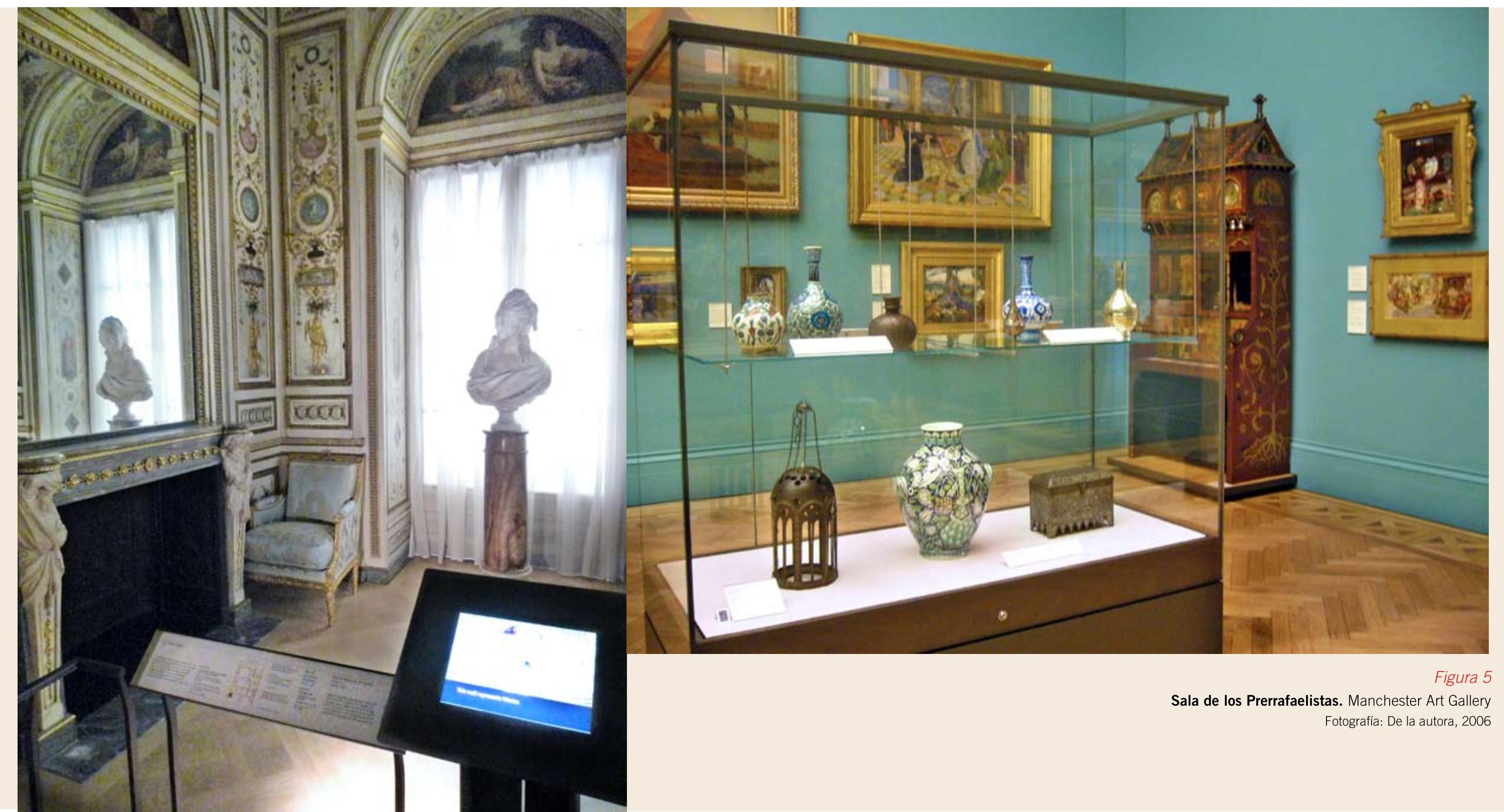




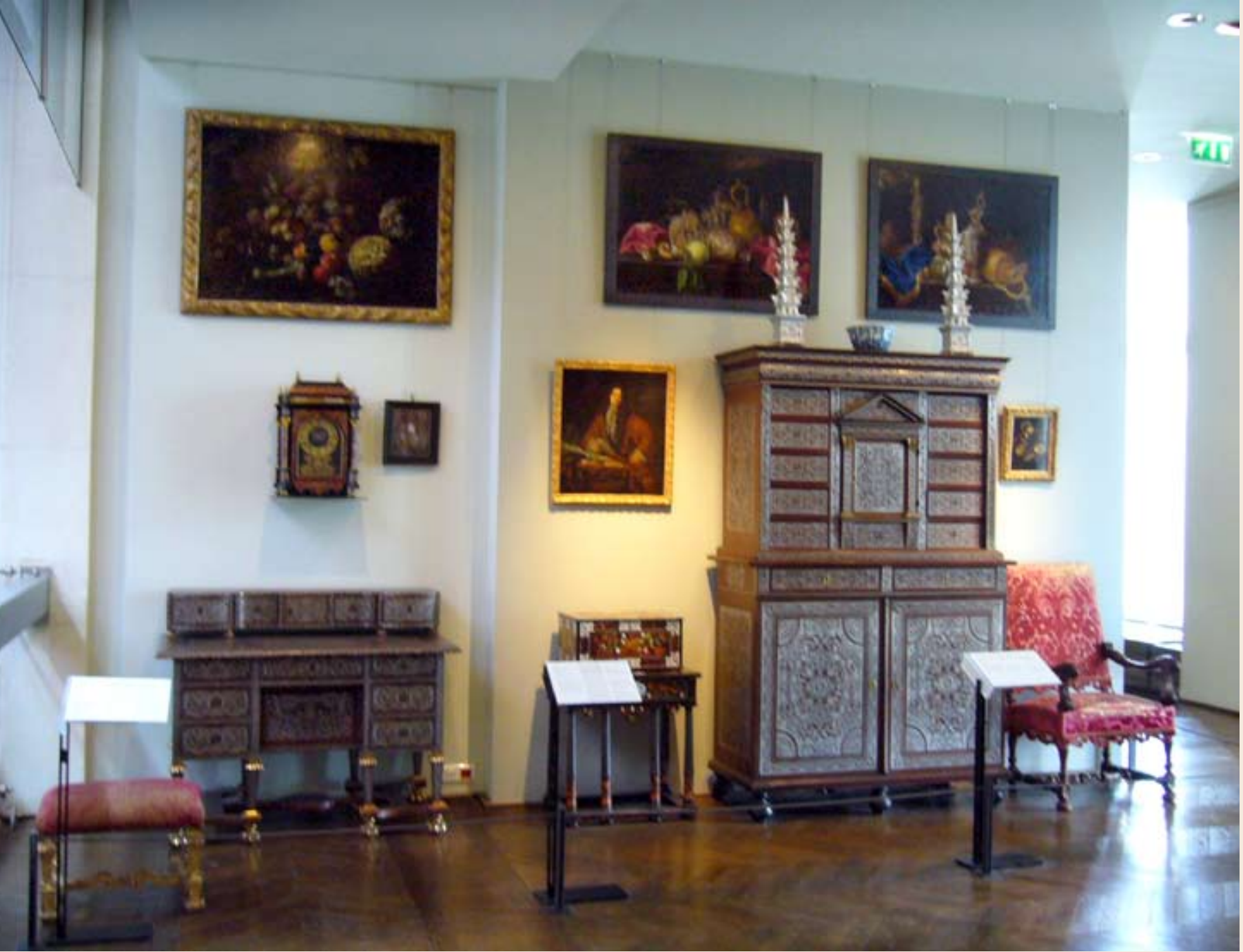

Figura 5

Musée des Arts Décoratifs. Paris

Fotografía: De la autora, 2007

Contrasta este caso con algunas salas de la exposición permanente del Musée des Arts Décoratifs de París (Fig. 6), con una colocación de las piezas que no ayuda a su interpretación. En la sala que ponemos como ejemplo se exponen piezas del siglo XVII. Pudieron pertenecer perfectamente a una misma colección e, incluso, a una misma casa. Sin embargo, del modo en que están dispuestos estos objetos, no deducimos que una vez pudieron formar parte de una misma estancia. El mobiliario y la pintura en un interior tienen una función específica, pero aquí no se percibe y surgen las siguientes preguntas: ¿cómo se utilizarían los asientos expuestos?, el reloj que está colgado en el muro ¿se colocaría sobre una mesa?, ¿nos dicen algo las pinturas sobre sus poseedores?, ¿las piezas cerámicas colocadas sobre el armario-escritorio estarían así dispuestas en origen?

Los conocimientos sobre la historia del coleccionismo y del diseño de interiores ${ }^{29}$ poco a poco se van vertiendo en las instalaciones de los museos, como sucede en la sala procedente de The Grove, Harborne del V\&A, en la que se exponen piezas de cerámica azul y blanca tal y como el coleccionista Kendrick las tenía dispuestas ${ }^{30}$, de manera que aporta una información visual muy valiosa acerca del coleccionismo del siglo XIX en Inglaterra. También podríamos reseñar la casa museo de Víctor Hugo en París, donde los objetos que se exponen en las distintas salas recrean de manera bastante precisa cómo era un hogar burgués correspondiente a la élite cultural del siglo XIX.

\section{SALAS DE ÉPOCA Y RECREACIÓN DE AMBIENTES EN ESPAÑA 31}

Los museos más significativos de recreación ambiental son los que creó el marqués de la Vega-Inclán (1858-1942) y que en 1931 pasaron a manos del Estado: el Museo Romántico, el Museo del Greco en Toledo y la Casa Museo de Cervantes en Valladolid32. En 1924 funda el Museo Romántico, instalado en un edificio construido en 1773 y formado por un conjunto de pinturas, libros, objetos decorativos y muebles donados por el marqués al Estado. En sus salas se recreaba la vida de la época romántica, constituyendo un museo de una tipología inédita hasta el momento ${ }^{33}$. En la reciente reforma se ha trabajado intensamente para lograr que el visitante tenga una experiencia global evocadora. Se ha recreado la vida en una casa burguesa del siglo XIX a través de las colecciones del museo: pinturas, esculturas, objetos de artes decorativas, estampas y un largo etcétera, procedentes de la colección del marqués de la Vega-Inclán, de depósitos de instituciones como el Museo del Prado o el Museo Nacional de Artes Decorativas y de adquisiciones realizadas por el Estado. Un aspecto interesante es que, por un lado está la realidad concreta: la casa, con los objetos que se encuentran en la misma; pero el museo también custodia un patrimonio inmaterial: los usos de la habitación, hábitos sociales, roles familiares, modas, gustos, etc. ${ }^{34}$

En el ámbito de las casas museo, el Museo Cerralbo, remodelado recientemente, es un ejemplo de reconstrucción histórica de excepcional rigor, que ha devuelto al museo la configuración de la casa del XVII marqués de Cerralbo tal y como estaba cuando aún se encontraba con vida 35 .

Por otro lado, tenemos como ejemplo problemático de musealización de espacios históricos los palacios y otros edificios de Patrimonio Nacional. Y decimos problemático porque se trata de conjuntos que están sujetos a usos variados, no sólo patrimoniales, puesto que aún están a disposición de la Casa Real para el cumplimiento de sus funciones de representación. De manera que los espacios a los que acceden los visitantes no siempre son los mismos y su amueblamiento puede variar. Además, a lo largo de su historia se han visto afectados por numerosas transformaciones y los profesionales se ven en muchos casos abocados a elegir por recrear un periodo histórico u otro en una misma sala o conjunto de salas. Lo que comparten estos casos de musealización de edificios históricos con la reconstrucción de interiores en los museos tiene que ver con las herramientas que se utilizan para la transmisión de información a los visitantes, así como ciertas soluciones expositivas.

Por falta de espacio no vamos a poder analizar más ejemplos de casa museo y recreaciones ambientales en España ${ }^{36}$. Pero sí que vamos a abordar, aunque sea brevemente, el caso del Museo Nacional de Artes Decorativas. El número 1 de esta revista fue dedicado al estudio de la historia del MNAD y gracias a los trabajos que aquí se han publicado tenemos hoy una visión mucho más justa de lo que fue el museo en sus inicios ${ }^{37}$. El Museo Nacional de Artes Industriales, su precedente, fue creado con fines pedagógicos, tomando como ejemplo el museo South Kensington de Londres, germen del actual Victoria \& Albert ${ }^{38}$. Uno de los fines fundamentales del MNAI (hoy MNAD) era el de exponer modelos para los artistas, diseñadores y trabajadores de las artes in- 
dustriales, por lo que el escaso espacio con el que contaba el museo para la exposición de las colecciones estaba aprovechado al máximo (Fig. 7).

En cuanto a la recreación de ambientes, hubo intención de exponer algunas de las colecciones en reconstrucciones ambientales. El Anuario del Museo de 1916 lo explica:

"En los trabajos de instalación se ha preocupado el personal en colocar los objetos de modo que se realce su valor artístico, y en cuanto sea posible, ponerlos en una disposición igual o parecida a la que tuvo el objeto al destinarlo al fin natura suyo. Cuando esto no ha podido realizarse, se ha hecho la instalación de modo que quite a las salas toda la aridez de cosa muerta o almacenada. En una instalación más perfecta -contando con amplio y apropiado local- se debería llegar, en muchos casos, a formar habitaciones completas, y así los objetos expresarían perfectamente su fin de utilidad. Esto unido a las instalaciones en series históricas y técnicas, debe ser el fin que se persigue, y que podrá lograrse cuando el número de objetos y local lo permitan." 39

El museo ejerció un papel muy activo en el campo de las exposiciones temporales, colaborando estrechamente con la Sociedad Española de Amigos del Arte en la organización de exposiciones sobre artes decorativas. En algunos casos, como la exposición

Figura 7

El Museo Nacional de Artes Industriales en la sede de la calle Sacramento. Hacia 1915.

Fotografía: Museo Nacional de Artes Decorativas. Madrid (FD11045). Ministerio de Educación, Cultura y Deporte, Madrid.

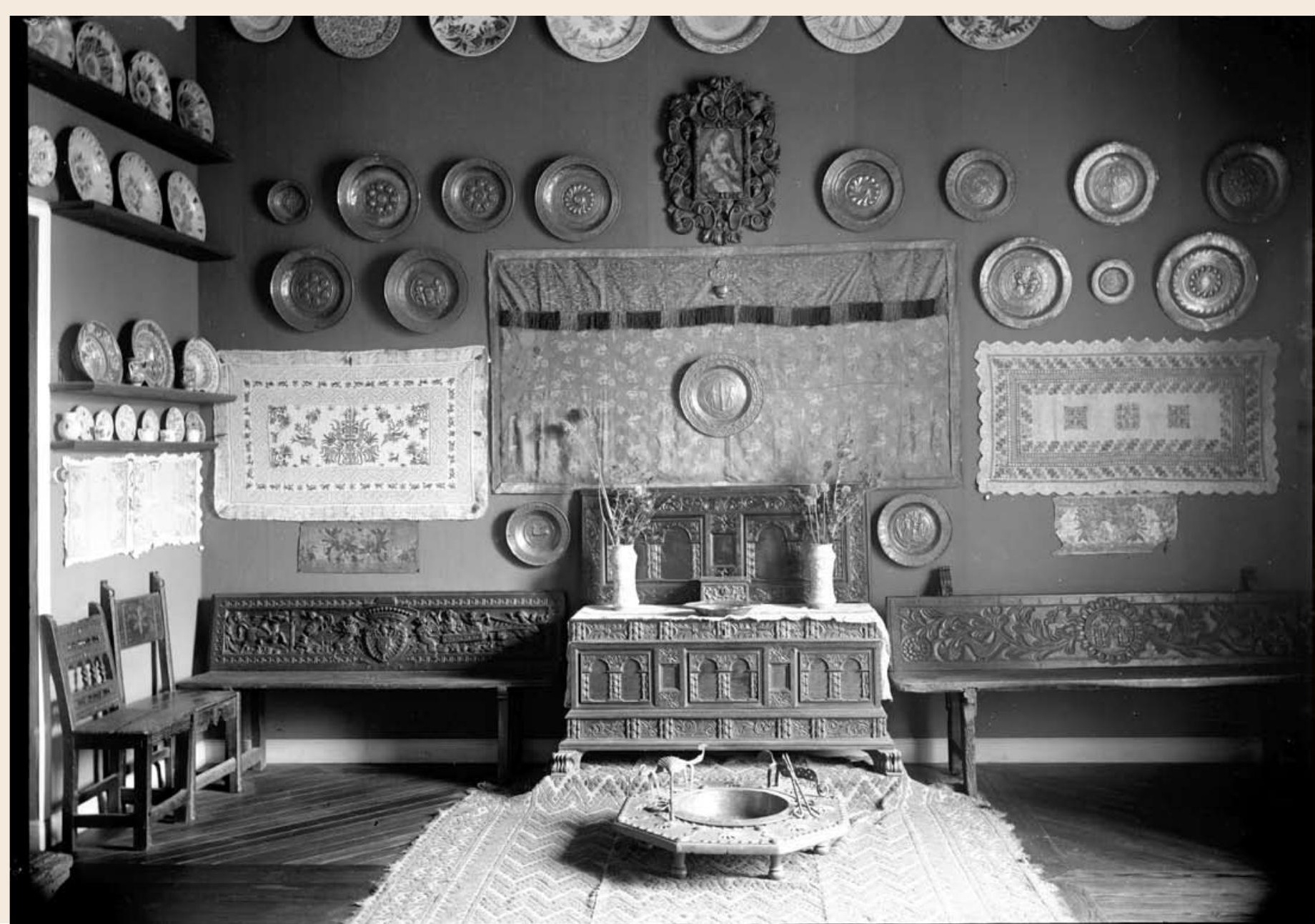

de bordados y encajes, un número muy elevado de piezas procedían de las colecciones del museo. En otros muchos, como la exposición del abanico en España, el museo prestaba algunas piezas que dotaban a la exposición de la ambientación necesaria ${ }^{40}$.

. . se compra la que podemos considerar la "period room"del MNAD, la cocina procedente de un palacio valenciano del siglo XVIII

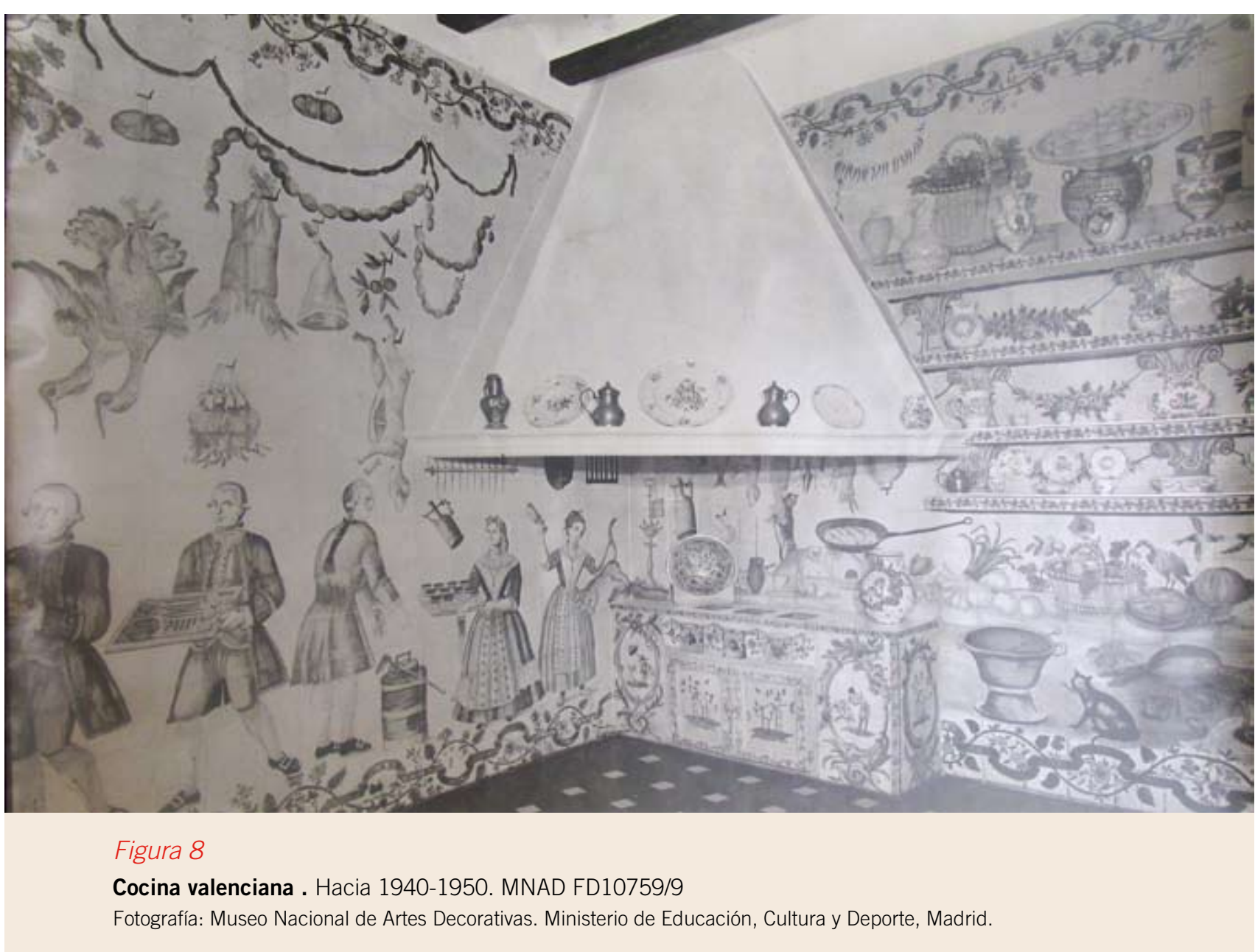

Poco antes de la Guerra Civil, estando el museo ya instalado en el palacete de la calle Montalbán y denominándose Museo Nacional de Artes Decorativas, se comenzó a preparar la exposición permanente de sus colecciones, que progresivamente fueron acrecentándose con numerosas donaciones de particulares y compras. En la década de 1940 se instalan en el museo un importante conjunto de techumbres de madera procedentes de palacios y conventos de varias provincias españolas. Estas techumbres se adaptan a la forma y medidas de las estancias del palacio. Asimismo se compra la que podemos considerar la period room del MNAD, la cocina procedente de un palacio valenciano del siglo XVIII (Fig. 8), vendida al Estado español e instalada en el museo en la década de 1940. La sala en la que se instalaron los paramentos de azulejería de la cocina se construyó con las dimensiones de la estancia original. El estudio más reciente publicado sobre esta sala nos informa de que debido a 
la estructura del museo, la entrada original se colocó donde actualmente hay una ventana y la puerta por la que los visitantes entran hoy en la cocina en origen era la puerta de servicio ${ }^{41}$. Esto afecta a la lectura que hacemos hoy de las escenas representadas en los azulejos, por lo que son aspectos de los que convendría informar a los visitantes de museo, con el fin de que tengan una experiencia museística rigurosa y lo más fiel a la realidad de la pieza que contemplan como sea posible.

En esos años se configura la museografía del museo que más tiempo va a perdurar una exposición de objetos agrupados cronológicamente y con cierta intención de crear una ambientación histórica (Fig. 9) y por materiales, en el caso de los cueros artísticos o el vidrio. La agrupación de piezas seguía estando dominada por el horror vacui, pero esta tendencia se vio agudizada por el crecimiento de la colección.

La guía del museo de 1978 nos informa de la voluntad expresa de los técnicos del museo por crear ambientes en los que exponer piezas de periodos concretos (siglo XVII, siglo XVIII, siglo XIX) en un marco adecuado ${ }^{42}$. Esta estructura de las salas se ha mantenido con pocos cambios hasta la década de 1990, en la que se abordó una remodelación de las salas de las

Figura 9

Fola

Fotografía: Museo Nacional de Artes Decorativas. Ministerio de Educación, Cultura y Deporte, Madric

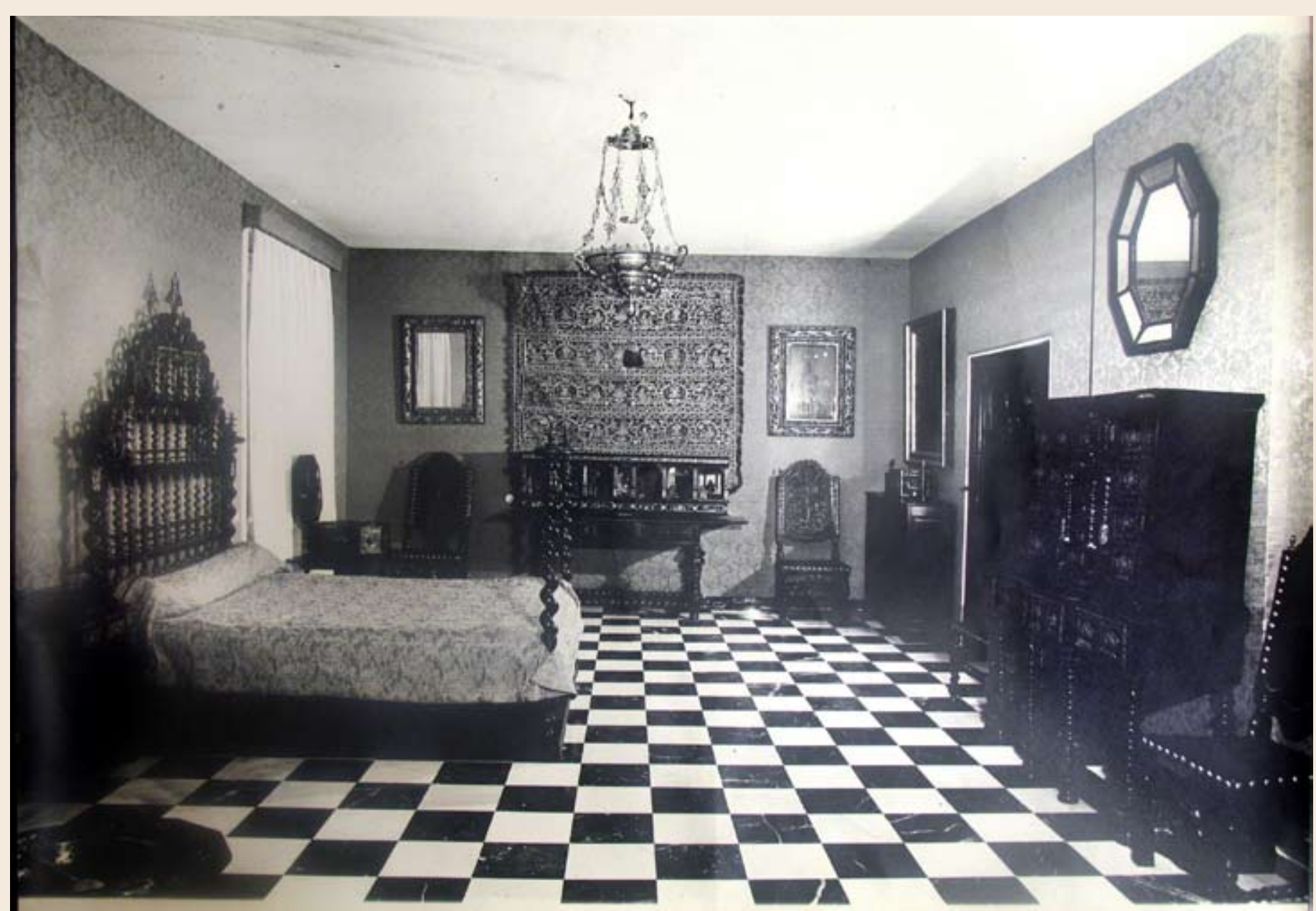

plantas tercera y cuarta, correspondientes a los siglos XVIII y XIX. El estudio y documentación de este proyecto, así como el análisis pormenorizado de las transformaciones que ha sufrido la museografía del museo a lo largo del periodo 1940-1970 están aún por hacer. Lo que sí podemos asegurar es que el museo se decantó por la recreación de ambientes de carácter doméstico y, muy probablemente marcado por el edificio en el que se encontraba, optó por representar los interiores de las clases pudientes de la sociedad, o al menos esa parece la intención. Otra cuestión que habría que analizar es si las piezas expuestas en un mismo ámbito correspondían a una misma clase social o contexto de uso. Lo que no nos atrevemos es a afirmar con rotundidad que no existiera una voluntad de realizar agrupaciones coherentes y sin falsear en exceso la visión que se daba de los interiores del pasado.

\section{CONCLUSIONES}

Queremos finalizar este trabajo subrayando el carácter innovador de la museografía recreadora de atmósferas y experiencias pasadas, pues responden a un concepto de patrimonio muy amplio, ya no sólo centrado en el monumento, sino que incluye el ámbito de lo doméstico y de las experiencias individuales de coleccionistas o habitantes de los interiores mostrados. En sí mismas, las salas de época constituyen recursos didácticos por su capacidad evocadora, por lo que encajan muy bien con las líneas de trabajo actuales en didáctica del patrimonio cultural, la didáctica de la experiencia.

Creemos que los argumentos que esgrimía Germain Bazin en contra de las period rooms han podido ser solventados según han avanzado las técnicas museográficas, por lo que su tesis ya no es defendible en la actualidad. Instalaciones como las del V\&A nos demuestran que la combinación de salas de exposición temática o técnica con reconstrucciones de interiores de épocas concretas y conjuntos originales enriquecen muchísimo la visita al museo. Los museos anglosajones tienen muy claro que deben dirigirse al gran público, para quien puede ser más fácil aproximarse al pasado transportándose directamente al mismo.

En la actualidad, el MNAD se encuentra en un momento de redefinición de sus fines y ámbito de trabajo. De museo de artes decorativas se querría pasar a ser un museo del diseño, con las implicaciones que esto conlleva. Al pasar a ser un museo dedicado al diseño los límites de las colecciones se ampliarían y la finalidad de la institución estaría marcada por el objetivo de transformación de la sociedad que los movimientos de reforma del diseño industrial propugnaron desde inicios del siglo XX. Acerca de cómo integrar las artes decorativas en un discurso tan radicalmente diferente habrá que dedicar muchos esfuerzos.

Consideramos que se debería estudiar con detenimiento la posibilidad de utilizar, en algunos casos y siempre con el máximo rigor, la recreación de ambientes y la instalación de salas de época en el museo, con el fin de facilitar la visita, pues ya hemos observado más arriba cuáles son las posibilidades que ofrece. Sería interesante que se pudiera realizar un estudio de público al respecto que analizara la reacción del visitante al encontrarse con este tipo de museografía. Pensamos que ayudaría a conocer la capacidad evocadora de estos espacios y su pertinencia en el discurso expositivo. 


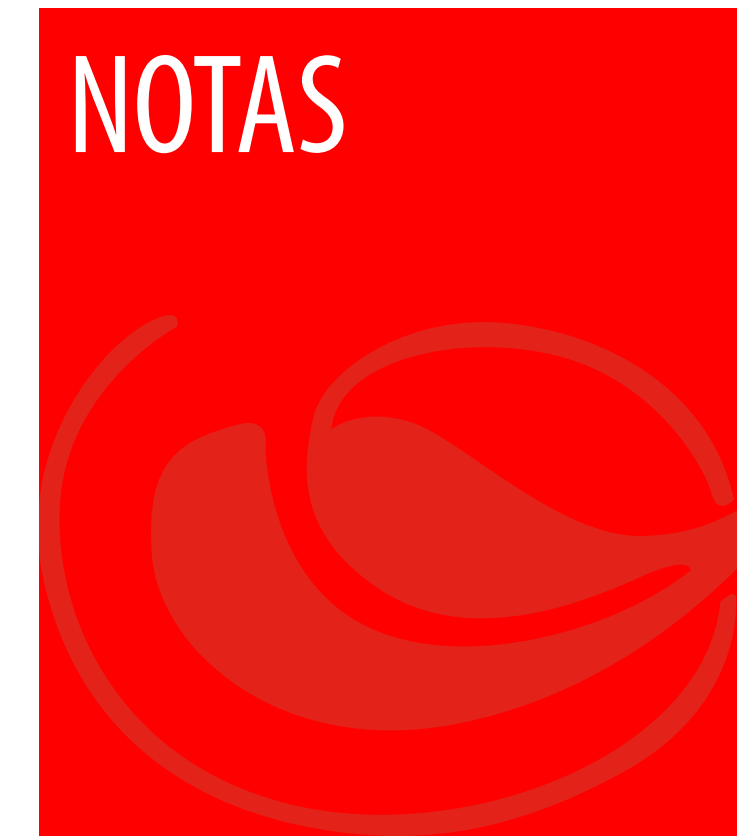

1 Para aproximarse al concepto posmoderno de proyecto expositivo, véase "Los Inmateriales, una dramaturgia postmoderna" en BOLAÑOS, M. (ed.), La memoria del mundo. Cien años de museología (1900-2000), Gijón, Ediciones Trea, 2002, pp. 384-387 y “Lo que importa es la idea, no el objeto", Idem, pp. 308-313. Resulta clarificador el texto de FABIANI, J.-L, "Le plaisir, le devoir et la science. Un regard sociologique sur la productivité muséale" en Histoire de l'art et musées. XVIIIe Rencontres de l'École du Louvre, París, École du Louvre, 2005, pp. 127-131.

2 GÓMEZ MARTíNEZ, J., Dos museologías. Las tradiciones anglosajona y mediterránea: diferencias y contactos, Gijón, Ediciones Trea, 2006.

${ }^{3}$ RIVIÈRE, G.H., La Museología. Curso de Museología / Textos y testimonios, Torrejón de Ardoz (Madrid), Ediciones Akal, 1993, pp. 76-77. El fragmento citado procede de BAZIN, G.: Le temps des musées, Lieja/Bruselas, Desoer, 1967, p. 302.

${ }^{4}$ BAZIN, G., ob. cit., pp. 250-252.

${ }^{5}$ Idem, p. 250

${ }^{6}$ lbidem.

7 Ibidem.

${ }^{8} \mathrm{http}: / /$ www.carnavalet.paris.fr/fr/node/351/en-savoir-plus-sur-le-musee-carnavalet (consulta: junio de 2013)

9 WILK, C. y HUMPHREY, N. (eds.), Creating the British Galleries at the V\&A: A Study in Museology, Londres, V\&A Publications, 2004, pp. 165-166.

${ }^{10}$ Desde el año 1995 el museo Victoria \& Albert ha emprendido una remodelación profunda de su exposición permanente. Las nuevas salas dedicadas al arte de Europa y Gran Bretaña, desde el Renacimiento hasta el siglo XIX realizan una síntesis entre la exposición de carácter didáctico y aquella que permite un análisis pormenorizado de materiales y técnicas, sin dejar de ofrecer en ningún momento una visita atractiva desde el punto de vista estético e intelectual. Véase MILLER, L.E., “Europe 1600-1800 in a Thousand Objects” en GERRITSEN, A. y RIELLO, G. (eds.), Writing Material Culture History, Londres, Bloomsbury, 2014, pp. 241-248.

${ }^{11}$ JAYNE, H. H. F., “Le nouveau Musée d’Art de Philadelphie”, Mouseion, núm. 4, 1928, p. 21.

12 GUGLIELMO, A. M. y FLEMING, R., “Digitizing the Libraries' Collections: Industrial Arts at the Metropolitan Museum, 1917-40", Nueva York, 30 de julio de 2012 [http://www. metmuseum.org/blogs/now-at-the-met/features/2012/industrial-arts-at-the-metropolitanmuseum] (consulta: septiembre de 2016).

13 "L'Institut d'Art de Detroit et la Théorie moderne des Musées", Mouseion, 9, 1929, pp. 283-287.

${ }^{14}$ Idem, p. 283.

15 /dem, p. 285.

16 PECK, A. et al., Period Rooms in the Metropolitan Museum of Art, Nueva York, The Metropolitan Museum of Art, 1996, p. 9.

${ }^{17}$ Idem, p. 10.

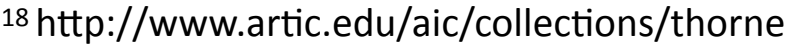

19 Véase el catálogo de la exposición Hans Haug, homme de musées: une passion à l'oeuvre. Galerie Heitz, château des Rohan, Estrasburgo, 2010.

20 PUYVELDE, L. van, "Principes de la présentation des collections dans les musées", Mouseion vols. 25-26, 1934, pp. 36-43. Citado por GÓMEZ MARTíNEZ, J., ob. cit., pp. 165-166.

${ }^{21}$ Ibidem

22 Véase "Una nueva tendencia expositiva, los period rooms" en BOLAÑOS, M., ob. cit., pp. 104-106

${ }^{23}$ RIVIÈRE, G. H.,“Victoria and Albert Museum”, ICOM News, 2, p. 4. Citado por GÓMEZ MARTÍNEZ, J., ob. cit., pp. 166-167.

${ }^{24}$ Véase el texto de Peter Thornton de 1991 acerca de la redistribución del mobiliario en el interior de Osterley: "An Historic House Interior: Osterley" en BEARD, G. (ed.), Country Houses and Collections. An Anthology, The Attingham Trust for the Study of Country Houses and Collections, 2002, pp. 27-29.

25 BAZIN, G., ob. cit., p. 252

${ }^{26}$ WILK, C. y HUMPHREY, N. (eds.), ob. cit.

${ }^{27}$ Idem.

28 MILLER, L., “Rediscover Europe 1600-1815: From Rome to Waterloo”, V\&A Magazine, 38 2015. Agradezco a Lesley Miller la amabilidad de transmitirme este texto. 
${ }^{29}$ Es preciso destacar el Centre for the Study of the Domestic Interior del AHRC, fruto de la colaboración durante cinco años del Royal College of Art, el V\&A Museum y The Bedford Centre for the History of Women at Royal Holloway, de la Universidad de Londres. Véase AYNSLEY, J. et al. (eds.), Imagined Interiors: Representing the Domestic Interior since the Renaissance, Londres, V\&A Publications, 2006.

30 http://www.vam.ac.uk/content/articles/s/style-guide-aestheticism/ (consulta: junio de 2013).

31 En relación con este tema debemos citar la tesis doctoral (inédita) de Soledad Pérez Mateo dedicada a las Casas Museo en España, leída en la Universidad de Murcia en 2016.

32 BOLAÑOS, M.: Historia de los museos en España. Memoria, cultura, sociedad, Gijón, Ediciones Trea, 2008 (2ª edición), p. 308.

33 Idem, p. 309.

34 Véanse los textos de Begoña Torres González en: Revista del Museo Romántico, 1 (1998) y 5 (2006); "Consideraciones sobre el nuevo plan museológico del Museo Romántico", Museo. Revista de la Asociación Profesional de Museólogos de España, 13, 2008, pp. 169-187 y VV.AA., Casas Museo. Museología y gestión, Madrid, Ministerio de Educación, Cultura y Deporte, 2013 (Actas de los Congresos sobre Casas Museo de 2006, 2007 y 2008).

35 Véase VAQUERO ARGÜELLES, L., "De casa a museo y de museo a casa”, en VV.AA., ob. cit., pp. 135-144.

36 Véanse las actas sobre Casas Museo ya citadas.

37 Véanse los artículos de Sofía Rodríguez Bernis, María Villalba Salvador y Ana Cabrera Lafuente.

${ }^{38}$ Véanse las últimas publicaciones sobre la historia del V\&A: BRYANT, J. (ed.), Art and design for all. The Victoria and Albert Museum, Londres, V\&A, 2011; BURTON, A., Vision and accident. The story of the Victoria and Albert Museum, Londres, 1999; y BAKER, M. \& RICHARDSON, B. (eds.), A grand design, Londres, 1997.

${ }^{39}$ Anuario del Museo Nacional de Artes Industriales, Madrid, 1916, pp. 9-10.

${ }^{40}$ En el archivo de Sociedad Española de Amigos del Arte, que custodia el archivo del Museo Nacional del Prado, se pueden ver fotografías de los montajes de las diversas exposiciones.

${ }^{41}$ ALONSO SANTOS, M., "La cocina de azulejos del Museo Nacional de Artes Decorativas" en CABRERA, A., RODRÍGUEZ, I. y VILLAR, C. (coords.), La cocina valenciana del Museo Nacional de Artes Decorativas. Una relectura a través de la tecnología de la Realidad Aumentada, Madrid, Ministerio de Educación, Cultura y Deporte, 2013 (publicación electrónica), pp. 39-60.

42 ENRíQUEZ, M. D., Guía del Museo Nacional de Artes Decorativas, Madrid, Ministerio de Educación y Ciencia, 1978. 